\title{
Frequency-Dependent $Q$ in the Earth's Outer Core from Short-Period P4KP/PcP Spectral Ratio
}

\author{
Satoru Tanaka* and Hiroyuki Hamaguchi \\ Observation Center for Prediction of Earthquakes and \\ Volcanic Eruptions, Faculty of Science, \\ Tohoku University, Aoba-ku, Sendai 980, Japan
}

\begin{abstract}
The attenuation of P-waves and its frequency dependence in the Earth's outer core are investigated using the P4KP/PcP spectral amplitude ratio. We analyze PcP and P4KP phases recorded on short-period seismographs in the Japan Islands for three large intermediate-depth and deep earthquakes from March 1991 through July 1994. The observed P4KP/PcP spectral amplitude ratio is corrected for responses of the mantle and the core, and attenuation in the lower mantle. The responses for P4KP and PcP are considered for the frequency dependence of their reflection/transmission coefficients at the core-mantle boundary. After the corrections, we estimate $Q_{\mathrm{P}}$ values in the outer core in the frequency range of $0.15-2 \mathrm{~Hz}$, and find that the $Q_{\mathrm{P}}$ increases with increasing frequency $(f)$ in the form of $Q_{\mathrm{P}}=(4,600 \pm 100) f^{(0.55 \pm 0.07)}$. The observed frequency-dependent $Q_{\mathrm{P}}$ values increase more slowly with increasing frequency than those predicted by the model of the bulk attenuation based on the relaxation mechanism of immiscible particles in the outer core.
\end{abstract}

\section{Introduction}

The anelastic property in the Earth's outer core has been discussed not only regarding viscosity but also as a relaxation mechanism. Knowledge of the physical properties of the outer core is essential to understand convection flow generating the geodynamo, the light-element solute in the outer core, and the core-mantle coupling which strongly relates to the Earth's rotation (e.g., Anderson, 1980; Stevenson, 1983; Lumb and Aldridge, 1991).

Seismic attenuation, represented by the quality factor $Q$, in the outer core has been estimated in wide frequency ranges. For the frequency around $1 \mathrm{~Hz}$, the P-wave attenuation $\left(Q_{\mathrm{P}}\right)$ has been inferred in various ways: as 2,000-10,000 from the amplitude ratio of PnKP phases which traverse the mantle and the outer core as $\mathrm{P}$-waves and reflecting $(n-1)$ times at the underside of the core-mantle boundary (CMB) (Buchbinder, 1971, 1972; Adams, 1972; Qamar and Eisenberg, 1974), as 3,000-10,000 from the spectral ratio between $P$ and $P^{\prime} P^{\prime}$ (Sacks, 1971), and as 10,000 to infinity from the spectral ratio of $\mathrm{P} 7 \mathrm{KP} / \mathrm{P} 4 \mathrm{KP}$ (Cormier and Richards, 1976). Except for the results of Cormier and Richards, all of the earlier results from the study of PnKP phases have a flaw because of neglecting the tunneling effect and frequency dependence of the reflection/transmission coefficients at the CMB. For the frequency around $0.05 \mathrm{~Hz}$, the $Q_{\mathrm{P}}$ in the outer core was estimated as 100-300 using the SKS/ScS spectral slope (Suzuki and Sato, 1970). However, this result also includes a flaw because the frequency dependence of the transmission coefficients for the SKS phase was negleted. For frequencies lower than $0.005 \mathrm{~Hz}$, an analysis of free oscillations suggested that $Q$ is inversely proportional to frequency (Anderson, 1980). Recently, Widmer et al. (1991) modeled the intrinsic attenuation of seismic energy between 0.3 and $10 \mathrm{mHz}$ with a frequency-independent $Q$ model. In their model, the bulk attenuation $\left(Q_{k}\right)$ value in the outer core is 12,000 . In general, $Q_{\mathrm{P}}$ is equal to $Q_{k}$ in the outer core. We have generally believed that a very large $Q$ value in the outer core is reasonable.

In contrast, Anderson and Given (1982) proposed that the absorption band $Q$ in the outer core lies in the frequency range of $0.01-0.1 \mathrm{~Hz}$, based on the theory of seismic attenuation (e.g., Kanamori and Anderson, 1977) assuming a minimum $Q_{k}$ value of

Received July 19, 1995; Accepted May 9, 1996

* To whom correspondence should be addressed. 
400 at the frequency of about $0.02 \mathrm{~Hz}$. The frequency behavior of $Q$ is an important clue for discussing the size and density of an immiscible blob composed of light elements in the outer core (Stevenson, 1983). Unfortunately, there have been no clear observations supporting the prediction by the absorption band $Q$ model that $Q$ in the frequency range higher than $0.1 \mathrm{~Hz}$ is proportional to a frequency with nearly constant $Q$ for $0.01-0.1 \mathrm{~Hz}$. Even the minimum $Q$ value has not been confirmed as discussed above. In the present study, we analyzed shortperiod core phases to determine $Q_{\mathrm{P}}$ values in the outer core at the frequency around $1 \mathrm{~Hz}$, and searched for evidence for the frequency dependence of the $Q_{\mathrm{p}}$.

In order to determine $Q_{\mathrm{P}}$ values in the outer core, PnKP phases are the most suitable because of their long path legs in the outer core. Before the 1980s, PnKP phases were analyzed only using large seismic arrays such as LASA (Engdahl, 1968) and Yellowknife (Wright, 1973) or a low-noise seismic station located in a stable continent (Buchbinder, 1972). The total number of observations of PnKP phases had been very small. Now it is easy to find PnKP phases even in the Japan Islands because tremendous effort has been put into the construction of Japanese seismic stations on low-noise sites under several earthquake prediction programs, and because digital and continuous recording began in March 1991. We analyzed data from the J-Array program (see for details J-Array Group, 1993), an integrated seismograph network for the observation of microearthquakes. Many representative waveforms collected by the J-Array from April 1991 to July 1992 were edited by Morita (1994). We additionally analyzed data from the network of the Observation Center for Prediction of Earthquake and Volcanic Eruptions belonging to Tohoku University (hereafter TOHOKU).

Previous studies tried to eliminate the effects of the mantle and the crust by applying the ratios of amplitude or spectrum between two phases of which the ray paths are as similar as possible in the mantle and the crust but very different in the core. However, combinations of P4KP/P7KP (Qamar and Eisenberg, 1974; Cormier and Richards, 1976), and SKS/ScS (Suzuki and Sato, 1970) were not very appropriate for eliminating the effects of mantle heterogeneity because their ray paths in the mantle are completely different. Moreover the SKS/ScS results require carefully analysis because the

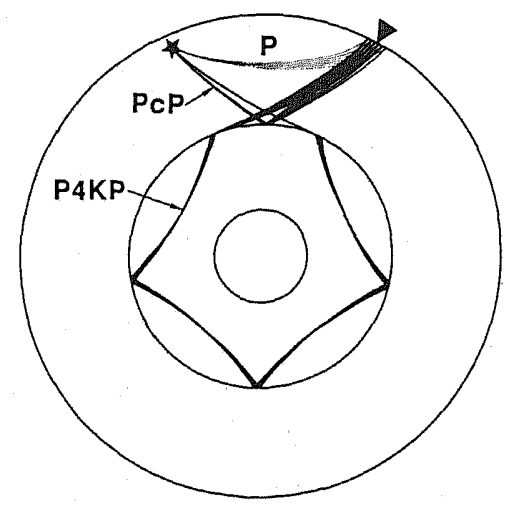

Fig. 1. Ray paths for $\mathrm{P}, \mathrm{PcP}$, and $\mathrm{P} 4 \mathrm{KP}-\mathrm{AB}$. Note that the ray paths of PcP and P4KP almost coincide with each other in the crust and the mantle except for the lowermost mantle, suggesting that a $\mathrm{P} 4 \mathrm{KP} / \mathrm{PcP}$ spectral ratio cancels out responses of the crust and most of the mantle.

transmission coefficient of SKS at the CMB has frequency dependence and is sensitive to the structure of the lowermost mantle (Silver and Bina, 1993; Garnero et al., 1993).

Here, we apply the P4KP and PcP phases as their ray paths almost coincide with in the crust and mantle, except for the lowermost mantle as shown in Fig. 1. The deepest point of the P4KP phase is about $1,000 \mathrm{~km}$ below the $\mathrm{CMB}$. The $\mathrm{AB}$ and $\mathrm{BC}$ branches of $\mathrm{P} 4 \mathrm{KP}$ travel times, as predicted by the Earth models of PEM-C (Dziewonski et al., 1975), PREM (Dziewonski and Anderson, 1981), iasp91 (Kennett and Engdahl, 1991), and SP6 (Morelli and Dziewonski, 1993) are shown in Fig. 2. The travel times for the AB branch using iasp91 and SP6 were very close (within $1 \mathrm{~s}$ ), but they were more than $3 \mathrm{~s}$ different from those using PEM-C and PREM. Travel times are sensitive to differences in the radius of the core and the velocity structure in the outermost $1,000 \mathrm{~km}$ of the core. The P4KP phase is not frequently observed in epicentral distances around cusp B, but observed around and beyond cut-off point A (Engdahl, 1968). This phenomenon is due to the frequency dependence of reflection/ transmission coefficients at the CMB and the tunneling effect (Aki and Richards, 1980). Therefore, after correcting the effect of velocity structure, we can determine the average $Q_{\mathrm{P}}$ value in the outermost $1,000 \mathrm{~km}$ of the core. 


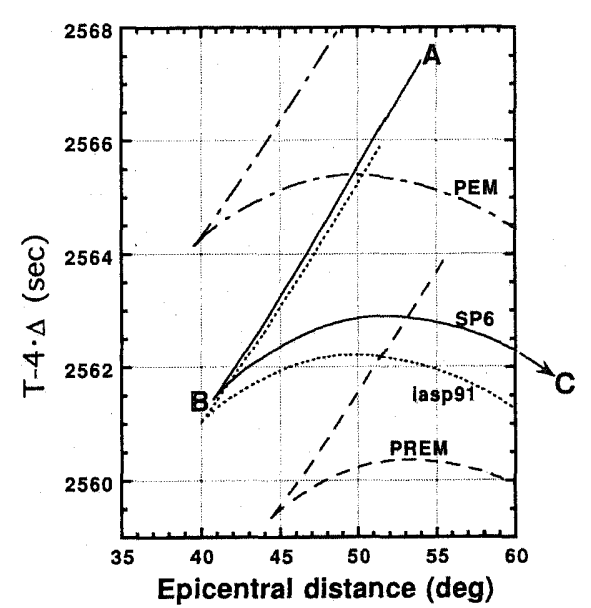

Fig. 2. P4KP travel times predicted by Earth models PEM-C, PREM, iasp91, and SP6. Focal depth is assumed to be $200 \mathrm{~km}$. Travel times are reduced by $4 \mathrm{~s} / \mathrm{deg}$. Points $\mathrm{A}$ and $\mathrm{B}$ are the cut-off point and the cusp point of P4KP, respectively. Cut-off point $C$ is out of range.

\section{Data}

We searched for P4KP and PcP phases in vertical short-period $\left(T_{0}=1 \mathrm{~s}\right)$ seismograms of the J-Array for dates before March 1993 and in data from TOHOKU for dates after April 1993. The sampling rates of the digital waveforms of the J-Array and TOHOKU data are 20 and $100 \mathrm{~Hz}$, respectively. We reduced the sampling rate of the TOHOKU data to $20 \mathrm{~Hz}$ after using same type anti-aliasing filter as that used for the J-Array data. Between March 1991 and July 1994, there were nine earthquakes with magnitudes and depths being equal to or greater than 6.2 and $100 \mathrm{~km}$, respectively, and having epicentral distances to Sendai $\left(38.3^{\circ} \mathrm{N}, 140.9^{\circ} \mathrm{E}\right)$ of $40-80^{\circ}$ (Fig. 3). We identified the P4KP phase for only three earthquakes: Flores Sea (Event 1) and the Afghanistan-USSR border region (Event 2) from J-Array data, and Hindu Kush (Event 3) from TOHOKU data. The epicenters of the three events are shown by the solid stars in Fig. 3, and their hypocenters are given in Table 1. Figure 4 shows the record sections for $\mathrm{P}$ and some later phases for each event. The theoretical travel times of the major phases are also plotted. A baseline shift of $5 \mathrm{~s}$ was added to the travel times for Event 1 to adjust predicted $\mathrm{P}$ arrivals to the observed big $\mathrm{P}$ arrivals. For events 1 and 2, we could easily identify the PcP

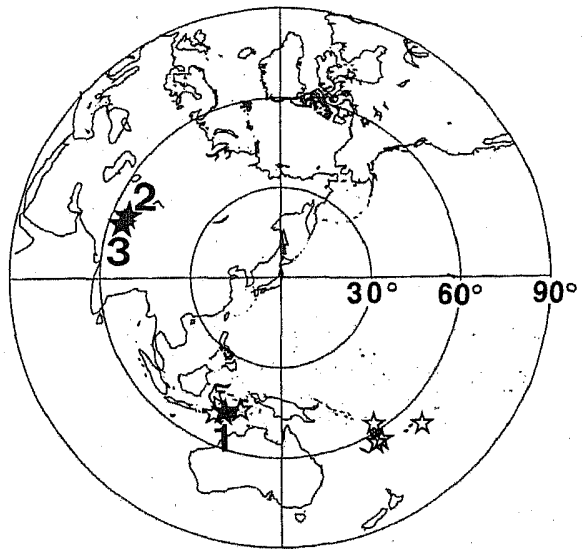

Fig. 3. Distribution of earthquakes for $m_{\mathrm{b}} \geq 6.2$, depth $\geq 100 \mathrm{~km}$, and $40^{\circ} \leq \Delta \leq 80^{\circ}$ from Sendai $\left(38.3^{\circ} \mathrm{N}, 140.9^{\circ} \mathrm{E}\right)$, in the period from March 1991 to July 1994. Solid stars indicate epicenters of the events for which P4KP phases were observed, and open stars are those for which P4KP were not observed. Numerals with the solid stars correspond to the event numbers listed in Table 1. This map is the equidistant azimuthal projection centered on Sendai and shows the regions of which distance from the center are less than $90^{\circ}$.

phases on the record sections and found no clear phases crossing PcP. Especially, the PcP phase for Event 1 appeared as an isolated phase in the distance range greater than $44^{\circ}$. For Event 2, the differential times of $\mathrm{PcP}-\mathrm{pP}$ decreased with increasing epicentral distance, suggesting that the $\mathrm{PcP}$ phases at larger distances are possibly contaminated by $\mathrm{pP}$ phases. The waveforms of Event 3 showed rather complicated features, having a low signal-to-noise ratio for the PcP phase.

Figure 5 shows record sections consisting of stations where both $\mathrm{PcP}$ and $\mathrm{P} 4 \mathrm{KP}$ phases are clearly observed for each event. The travel times were reduced by the appropriate slowness for each phase. The slowness of P4KP was about $4.4 \mathrm{~s} / \mathrm{deg}$, which shows good agreement with the theoretical value of 4.41-4.46 s/deg for the P4KP-AB branch predicted by Earth models such as PEM-C, PREM, iasp91, and SP6. We read the arrival times of PcP and P4KP phases, as marked by the solid circles in Fig. 5, and the differential travel times of P4KP-PcP are given in Table 2. 


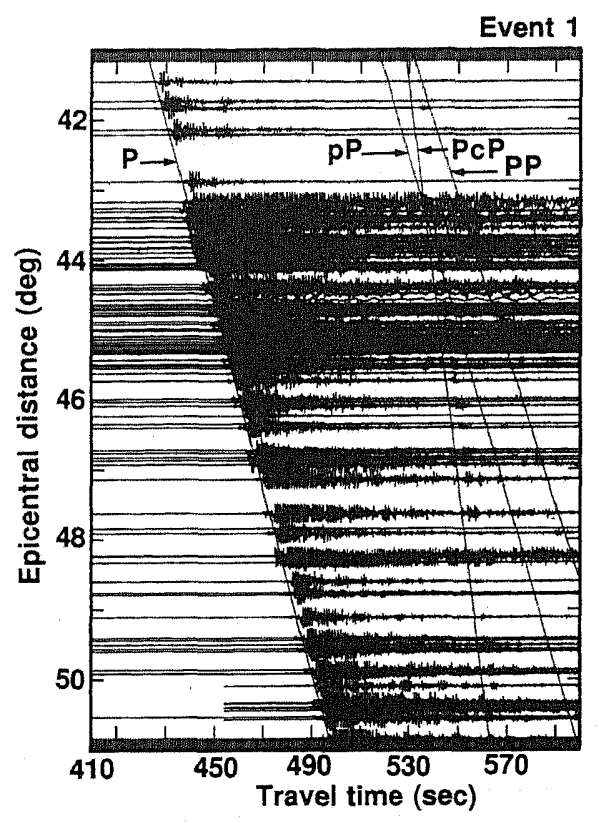

(a)

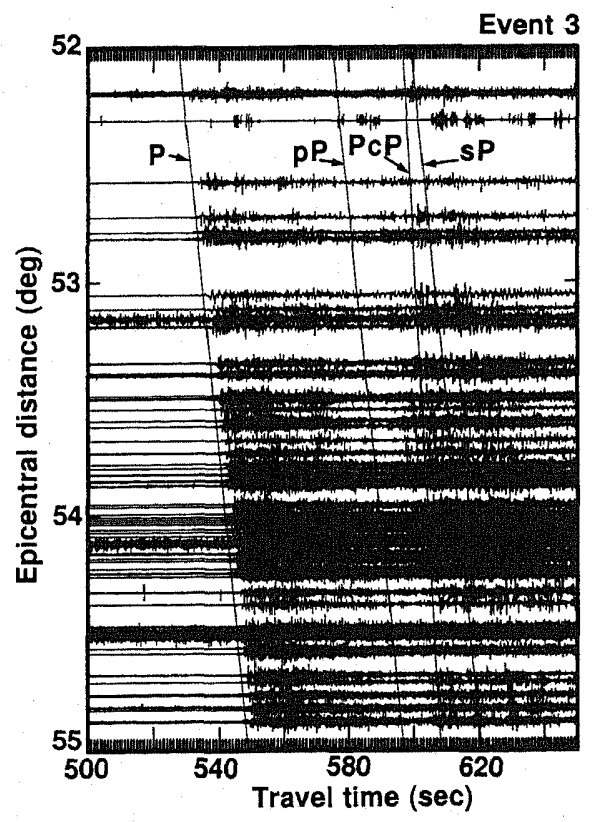

(c)

\section{Method}

The spectral ratio of the observed frequency spectrum of $\mathrm{P} 4 \mathrm{KP}, O_{\mathrm{P} 4 \mathrm{KP}}(\omega)$, with respect to that
Event 2

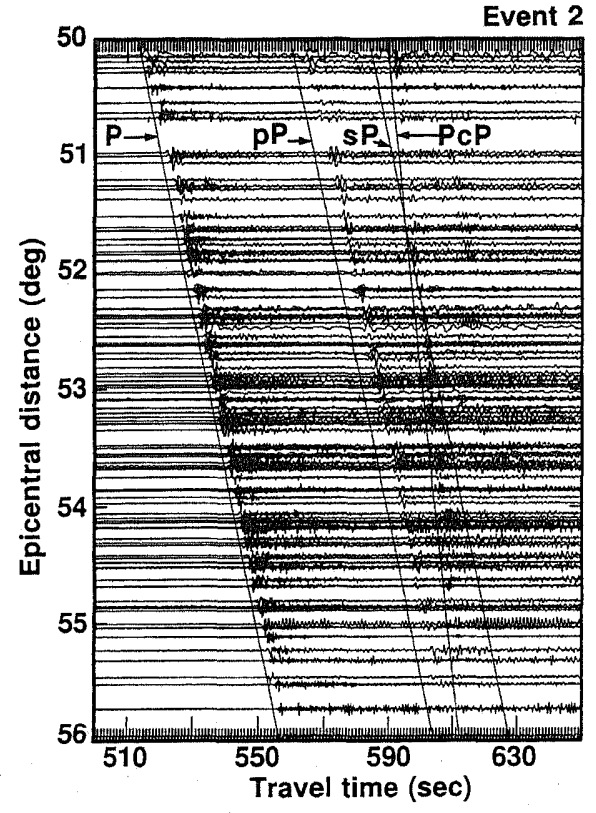

(b)

Fig. 4. (a) Record section of vertical short-period seismograms for Event 1 showing $P$ and other following phases. Predicted travel times of $P$, $\mathrm{pP}, \mathrm{PcP}$, and PP are given. The travel times include a baseline shift of $5 \mathrm{~s}$ to adjust predicted $\mathrm{P}$ travel times to the arrival of big $\mathrm{P}$ phases. Record sections for (b) Event 2, and (c) Event 3 show travel-time curves without a baseline shift.

of $\mathrm{PcP}, O_{\mathrm{PcP}}(\omega)$, is given by

$$
R(\omega)=\frac{O_{\mathrm{P} 4 \mathrm{KP}}(\omega)}{O_{\mathrm{PcP}}(\omega)},
$$


Table 1. List of hypocenters.

\begin{tabular}{ccccccc}
\hline Event No. & Date & Origin time & $\begin{array}{c}\text { Lat. } \\
(\mathrm{deg})\end{array}$ & $\begin{array}{c}\text { Long. } \\
(\mathrm{deg})\end{array}$ & $\begin{array}{c}\text { Depth } \\
(\mathrm{km})\end{array}$ & $\begin{array}{c}\text { Mag. } \\
\left(\mathrm{m}_{\mathrm{b}}\right)\end{array}$ \\
\hline 1 & $1991 / 06 / 07$ & $11: 51: 25.97$ & $7.204 \mathrm{~S}$ & $122.533 \mathrm{E}$ & 536 & 6.2 \\
2 & $1991 / 07 / 14$ & $09: 09: 11.91$ & $36.334 \mathrm{~N}$ & $71.119 \mathrm{E}$ & 213 & 6.4 \\
3 & $1993 / 08 / 09$ & $12: 42: 48.19$ & $36.379 \mathrm{~N}$ & $70.868 \mathrm{E}$ & 215 & 6.2 \\
\hline
\end{tabular}

Data from the monthly PDE.

where $\omega$ is the angular frequency and subscripts indicate the phase type. The observed spectrum $O(\omega)$ is expressed by

$$
O(\omega)=S(\omega) \cdot U(\omega) \cdot A(\omega) \cdot C(\omega) \cdot I(\omega),
$$

where $S(\omega)$ is the source spectrum, $U(\omega)$ is the response of the mantle and the core, $C(\omega)$ is the response of the crust, $I(\omega)$ is the instrumental response, and $A(\omega)$ is the attenuation factor described as

$$
A(\omega)=\exp \left(-\frac{\omega t^{*}}{2}\right)
$$

where $t^{*}=\int \mathrm{d} s /(Q \cdot \alpha)$ with $\mathrm{P}$ wave velocity, $\alpha$.

The responses of the mantle and the core for the P4KP phase, $\mathrm{U}_{\mathrm{P} 4 \mathrm{KP}}(\omega)$, were calculated by the full-wave theory given by Richards (1973) and Cormier and Richards (1976). Transmission coefficients at the $\mathrm{CMB}, T_{\mathrm{PK}}$ and $T_{\mathrm{KP}}$, and the reflection coefficient for the underside-reflection at the CMB, $R_{\mathrm{KK}}$, were given by Richards (1973) with the Langer approximation to consider the tunneling phenomena and the frequency dependence of these coefficients. Figure 6 shows the frequency dependence of the product of $T_{\mathrm{PK}} \cdot\left(R_{\mathrm{KK}}\right)^{3} \cdot T_{\mathrm{KP}}$ for P4KP for the Earth model SP6. The peak value of the product at the frequency of $0.1 \mathrm{~Hz}$ was less than one-third of that at $2 \mathrm{~Hz}$. The sensitivity of short-period seismometers around $0.1 \mathrm{~Hz}$ is very low $\left(10^{-2}\right.$ of that of around $1 \mathrm{~Hz}$ ). Therefore, we took into account only frequency ranges around $0.2 \mathrm{~Hz}$ and larger. Considering the sampling rate and the case of the Fast Fourier Transform, we adopted the data length of $6.4 \mathrm{~s}$, which corresponds to 128 points for the $20 \mathrm{~Hz}$ sampling. We calculated the response of the mantle and the core, $U_{\mathrm{P} 4 \mathrm{KP}}(\mathrm{w})$, by the integration along a path on the real ray parameter axis from 220 to $270 \mathrm{~s}$. The $U_{\mathrm{P} 4 \mathrm{KP}}(\omega)$ response depends on the $\mathrm{P}$ velocity structure at the base of the mantle and at the top of the core because the cut-off point $A$ of P4KP-AB changes according to the structure near the CMB. Therefore, we should carefully examine which Earth model is appropriate for calculating $U_{\text {P4KP }}(\omega)$. Here, we examined four global Earth models, PEM-C, PREM, iasp91, and SP6, using $\mathrm{P} 4 \mathrm{KP}-\mathrm{PcP}$ differential times.

The observed P4KP-PcP differential times were compared with those read on synthetic seismograms because some P4KP phases were observed beyond the distance predicted by the ray theory. Synthetics were obtained by convoluting $U_{\mathrm{P} 4 \mathrm{KP}}(\omega)$ with the instrumental response for a short-period seismometer (natural period: $T_{0}=1 \mathrm{~s}$, damping constant: $h=0.7$ ) and attenuation factor for the mantle predicted by PREM. Examples of synthetic seismograms with SP6 for a $213 \mathrm{~km}$ deep source are shown in Fig. 7. Times chosen as arrival times for PcP and P4KP were marked by solid circles on the synthetic seismograms. Figure 8 shows the residuals of the observed and theoretical P4KP-PcP times with respect to those predicted by SP6. Reading error is assigned as $\pm 0.5 \mathrm{~s}$. Residuals for the observed P4KP-PcP times are listed in Table 2. The residuals were well explained by those predicted by iasp91 and SP6, while those by PEM-C and PREM disagreed by about $4 \mathrm{~s}$ and $-3 \mathrm{~s}$, respectively. The differences in $\mathrm{PcP}$ travel times among the four models were within $1 \mathrm{~s}$, indicating that a large P4KP-PcP residual reflects a variation of P4KP travel time due to core structures such as core radius and/or $\mathbf{P}$ velocity in the outermost core. Here, we adopted the velocity structure of SP6 for the calculation of $U_{\mathrm{P} 4 \mathrm{KP}}(\omega)$ because the residuals around $\Delta=45^{\circ}$ indicate a better match to those for SP6 than those for iasp 91 .

The source spectral ratio of $S_{\mathrm{P} 4 \mathrm{KP}}(\omega) / S_{\mathrm{PcP}}(\omega)$ was assumed to be a constant. This constant, $S$, was estimated from the ratio of the source radiation pattern. The focal mechanisms of events 1,2 , and 
(a)
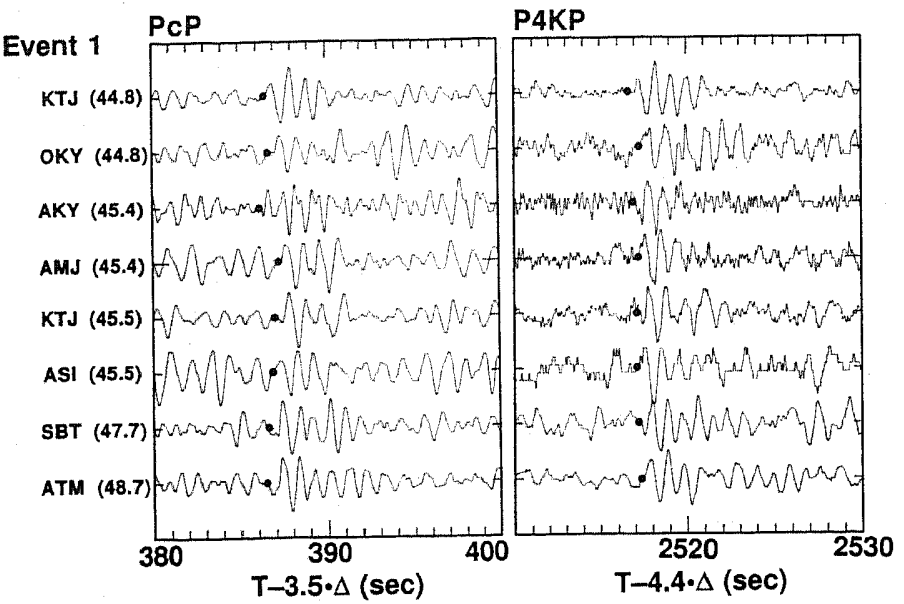

(b)

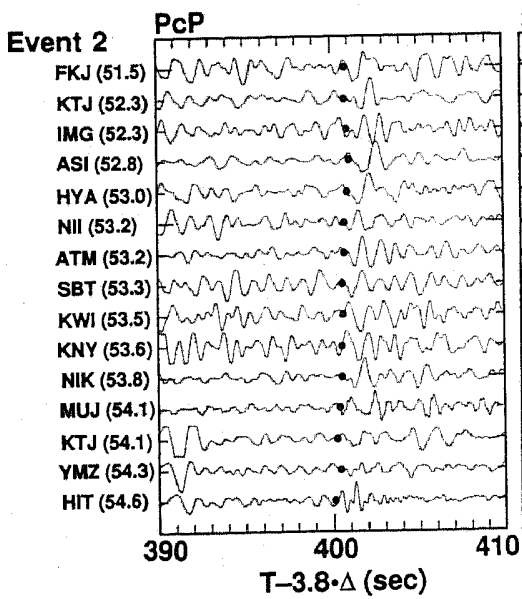

PAKP

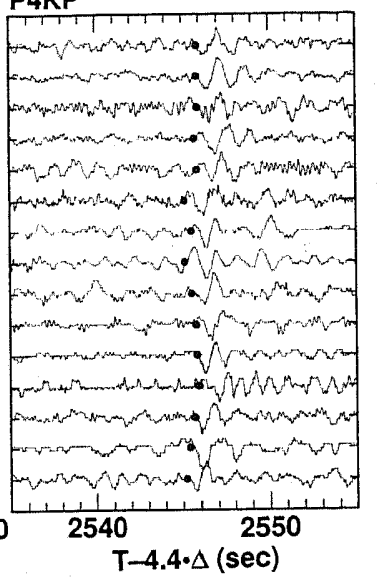

(c) Event 3

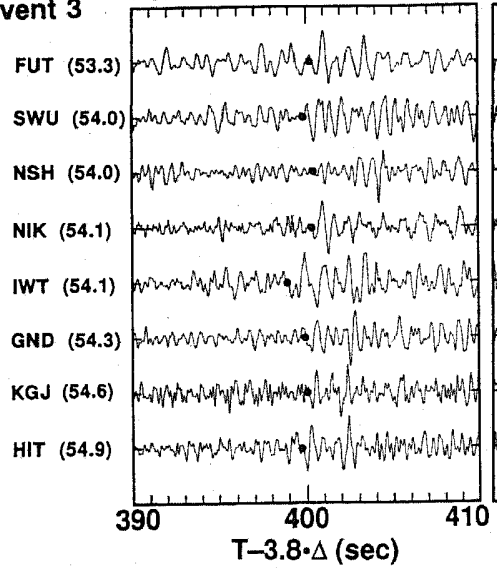

P4KP.

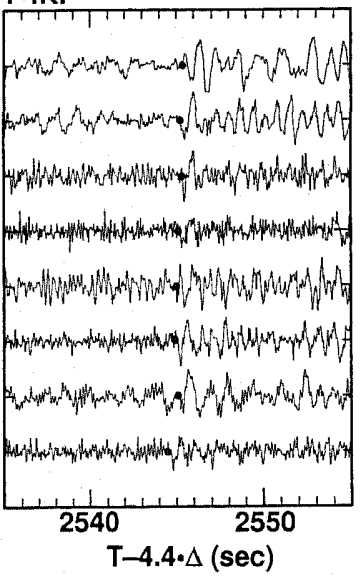

Fig. 5. (a) Record section of PcP (left) and P4KP (right) for Event 1. Travel times of PcP and P4KP are reduced by 3.5 and $4.4 \mathrm{~s} / \mathrm{deg}$, respectively. Solid circles represent the arrival times that we read. Station codes (epicentral distances) are labeled on the left side of the boxes. Record sections for (b) Event 2 and (c) Event 3 show the travel times of PcP reduced by $3.8 \mathrm{~s} / \mathrm{deg}$. 
Table 2. Observed differential travel times of P4KP-PcP and their residuals with respect to those predicted by SP6.

\begin{tabular}{|c|c|c|c|}
\hline Event No. & $\begin{array}{c}\Delta \\
(\mathrm{deg})\end{array}$ & $\begin{array}{c}\text { P4KP-PcP } \\
\text { (s) }\end{array}$ & $\begin{array}{c}\delta t_{\mathrm{P} 4 \mathrm{KP}-\mathrm{PcP}} \\
(\mathrm{s})\end{array}$ \\
\hline \multirow[t]{8}{*}{1} & 44.8 & $2,170.5$ & -0.3 \\
\hline & 44.8 & $2,171.0$ & 0.0 \\
\hline & 45.4 & $2,171.5$ & -0.1 \\
\hline & 45.4 & $2,170.8$ & -0.7 \\
\hline & 45.5 & $2,171.1$ & -0.5 \\
\hline & 45.5 & $2,171.2$ & -0.4 \\
\hline & 47.7 & $2,173.6$ & 0.1 \\
\hline & 48.7 & $2,174.4$ & 0.3 \\
\hline \multirow[t]{15}{*}{2} & 51.5 & $2,176.0$ & 0.1 \\
\hline & 52.3 & $2,176.4$ & 0.0 \\
\hline & 52.3 & $2,176.4$ & -0.1 \\
\hline & 52.8 & $2,176.4$ & -0.3 \\
\hline & 53.0 & $2,176.8$ & 0.0 \\
\hline & 53.2 & $2,176.3$ & -0.6 \\
\hline & 53.2 & $2,176.7$ & -0.1 \\
\hline & 53.3 & $2,176.5$ & -0.3 \\
\hline & 53.5 & $2,177.1$ & 0.0 \\
\hline & 53.6 & $2,177.4$ & 0.4 \\
\hline & 53.8 & $2,177.6$ & 0.4 \\
\hline & 54.1 & $2,178.0$ & 0.6 \\
\hline & 54.1 & $2,178.0$ & 0.5 \\
\hline & 54.3 & $2,177.6$ & 0.1 \\
\hline & 54.6 & $2,177.9$ & 0.2 \\
\hline \multirow[t]{8}{*}{3} & 53.3 & $2,177.2$ & 0.4 \\
\hline & 54.0 & $2,177.7$ & 0.5 \\
\hline & 54.0 & $2,177.3$ & 0.2 \\
\hline & 54.1 & $2,177.3$ & 0.0 \\
\hline & 54.1 & $2,178.5$ & 1.2 \\
\hline & 54.3 & $2,177.7$ & 0.2 \\
\hline & 54.6 & $2,177.9$ & 0.2 \\
\hline & 54.9 & $2,177.7$ & 0.0 \\
\hline
\end{tabular}

3 are shown in Fig. 9: one determined by P-wave polarity and the other by the Harvard Centroid Moment Tensor (CMT), which were taken from the monthly Preliminary Determination of Earthquakes. These two solutions were quite similar. The take-off angles and azimuths of $\mathrm{PcP}$ and $\mathrm{P} 4 \mathrm{KP}$ were almost the same. The ratios of the source radiation patterns of $\mathrm{P} 4 \mathrm{KP}$ to $\mathrm{PcP}$ assigned as the constant $S$ were $1.2,0.9$, and 1.0 for events 1,2 , and 3 , respectively.

Rewriting Eq. (1) under the assumption that $C(\omega)$ and $I(\omega)$ of the P4KP and PcP phases are canceled by applying the observed spectral ratio $R(\omega)$, the

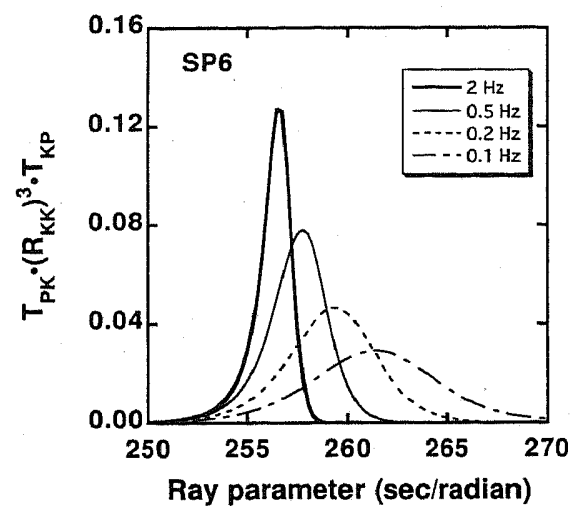

Fig. 6. The products of transmission and reflection coefficients, $T_{\mathrm{PK}} \cdot\left(R_{\mathrm{KK}}\right)^{3} \cdot T_{\mathrm{KP}}$, for P4KP phase as a function of ray parameters at frequencies of 2, $0.5,0.2$, and $0.1 \mathrm{~Hz}$ using the Earth model SP6.

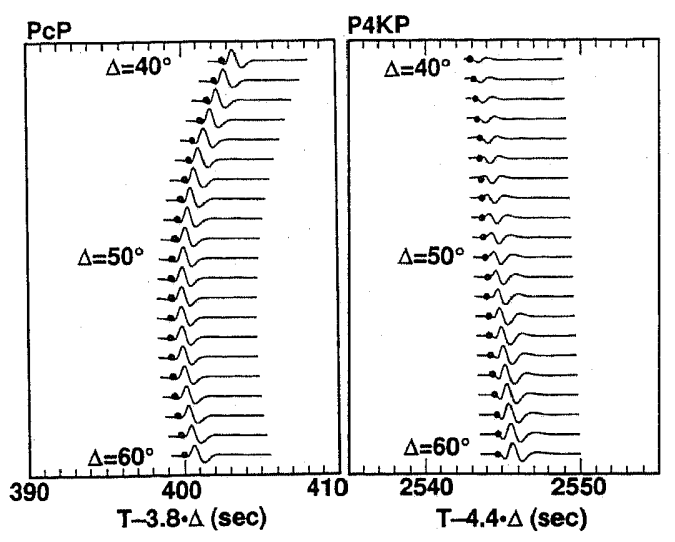

Fig. 7. Examples of synthetic seismograms of PcP (left) and P4KP (right) using the model SP6. Synthetics are obtained by convoluting the responses of PcP or P4KP with the instrumental response of a short-period seismometer and the attenuation factor in the mantle. Travel times are reduced by 3.8 and $4.4 \mathrm{~s} / \mathrm{deg}$ for $\mathrm{PcP}$ and $\mathrm{P} 4 \mathrm{KP}$, respectively. Focal depth is assumed to be $213 \mathrm{~km}$.

ratio of attenuation factor of $\mathrm{P} 4 \mathrm{KP}$ phases to that of $\mathrm{PcP}$ is given by

$$
\frac{A_{\mathrm{P} 4 \mathrm{KP}}(\omega)}{A_{\mathrm{PcP}}(\omega)}=\frac{1}{S} R(\omega) \frac{U_{\mathrm{PcP}}(\omega)}{U_{\mathrm{P} 4 \mathrm{KP}}(\omega)} .
$$

Using Eq. (2), we separate attenuation factor $A_{\mathrm{P} 4 \mathrm{KP}}(\omega)$ into those of the mantle and the core, and the left hand side of Eq. (3) becomes 


$$
\begin{aligned}
\frac{A_{\mathrm{P} 4 \mathrm{KP}}(\omega)}{A_{\mathrm{PcP}}(\omega)} & =\frac{\exp \left\{-\frac{\omega}{2}\left(t_{\mathrm{c}}^{*}+t_{\mathrm{m}}^{*}\right)\right\}}{\exp \left(-\frac{\omega}{2} t_{\mathrm{PcP}}^{*}\right)}, \\
& =\exp \left\{-\pi f\left(t_{\mathrm{c}}^{*}+t_{\mathrm{m}}^{*}-t_{\mathrm{PcP}}^{*}\right)\right\},
\end{aligned}
$$

where $t_{\mathrm{c}}^{*}$ is the $t^{*}$ in the outer core for $\mathrm{P} 4 \mathrm{KP}, t_{\mathrm{m}}^{*}$ is

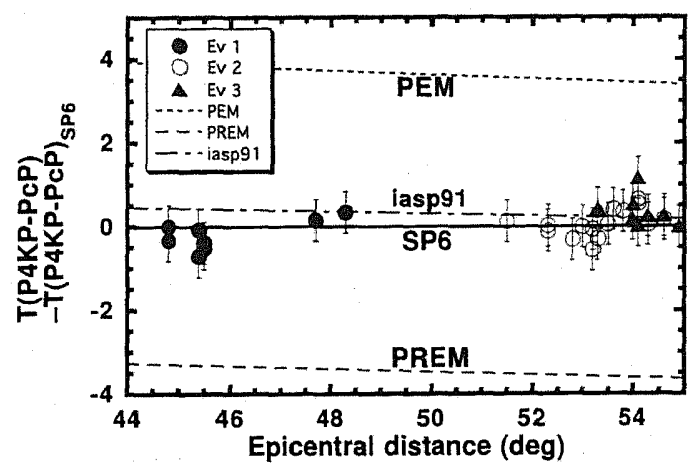

Fig. 8. Residuals of differential travel times P4KP$\mathrm{PcP}$ with respect to those predicted by the model SP6. Solid circles, open circles, and solid triangles represent residuals of the observed times for events 1,2 , and 3, respectively. The reading error of $\mathrm{P} 4 \mathrm{KP}-\mathrm{PcP}$ time is assumed to be $0.5 \mathrm{~s}$. Dashed, long dashed, and dash-dotted lines represent residuals for $\mathrm{P} 4 \mathrm{KP}-\mathrm{PcP}$ times predicted by PEM, PREM, and iasp91, respectively. the $t^{*}$ in the mantle for P4KP, $t_{\mathrm{PcP}}^{*}$ is the $t^{*}$ in the mantle for $\mathrm{PcP}$, and $f$ is the frequency $(=\omega / 2 \pi)$. Taking the natural logarithm of Eq. (3), we get

$$
\ln \left[\frac{1}{S} R(f) \frac{U_{\mathrm{PcP}}(f)}{U_{\mathrm{P} 4 \mathrm{KP}}(f)}\right]=\pi f\left(t_{\mathrm{c}}^{*}+t_{\mathrm{m}}^{*}-t_{\mathrm{PcP}}^{*}\right) .
$$

If we assume $Q_{\mathrm{p}}$ to be frequency-independent and constant in depth, we can infer $Q_{\mathrm{P}}$ of the outer core using the slope of the $\mathrm{P} 4 \mathrm{KP} / \mathrm{PcP}$ spectral ratio. While keeping the assumption that $Q_{\mathrm{P}}$ is constant in depth, the representation of frequency-dependent $Q_{\mathrm{P}}(f)$ in the outer core is,

$$
\begin{aligned}
Q_{\mathrm{p}}(f) & =\frac{T_{4 \mathrm{~K}}}{t_{\mathrm{c}}^{*}} \\
& =\frac{\pi f T_{4 \mathrm{~K}}}{\pi f\left(t_{\mathrm{m}}^{*}-t_{\mathrm{PcP}}^{*}\right)-\ln \left[\frac{1}{S} R(f) \frac{U_{\mathrm{PcP}}(f)}{U_{\mathrm{p} 4 \mathrm{KP}}(f)}\right]},
\end{aligned}
$$

where $T_{4 \mathrm{~K}}$ is the travel time of $\mathrm{P} 4 \mathrm{KP}$ in the outer core (about 2,000 s).

Since the path length of P4KP in the lowermost mantle is longer than that of $\mathrm{PcP}$, the $Q_{\mathrm{P}}$ structure in the lowermost mantle is critical for estimating $Q_{\mathrm{P}}$ in the outer core. Even if we assume that $Q_{\mathbf{p}}$ in the outer core is infinite, it is difficult to obtain a unique solution for a radial structure of $Q_{\mathrm{p}}$ in the lowermost mantle using the $\mathrm{P} 4 \mathrm{KP} / \mathrm{PcP}$ spectral ratio. Moreover, it is possible that lateral variation of the $Q_{\mathrm{P}}$ value, but this fact has not been fully revealed. Here,
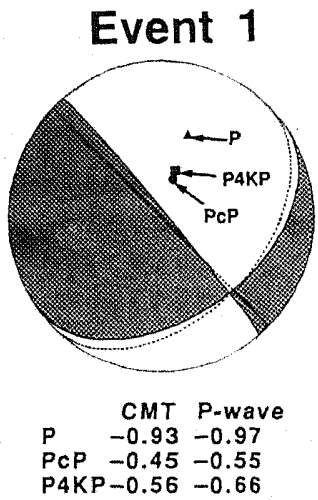

Event 2

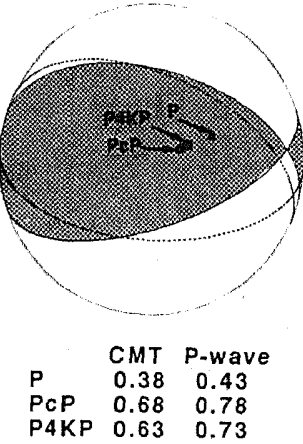

Event 3

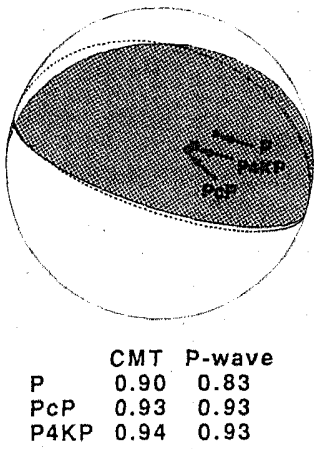

Fig. 9. The focal mechanisms of events 1,2, and 3 using an equal-area projection on the lower hemisphere of the focal sphere. Solid and broken lines show nodal planes of the CMT and P-wave, respectively. Triangles, circles, and squares are take-off angle and azimuth of $\mathrm{P}, \mathrm{PcP}$, and $\mathrm{P} 4 \mathrm{KP}$ phases, respectively. The hatched region shows a tension region of the CMT solution. Numerals below the focal mechanisms indicate radiation patterns of the phases for each solution. 
we consider two representative $Q$ models only for radial distributions in the mantle. The $Q_{\mathrm{P}}$ distribution in the lower mantle as a function of depth for PREM is almost constant $\left(Q_{\mathrm{P}} \approx 800\right)$, whereas SL8 (Anderson and Hart, 1978) shows that $Q_{\mathrm{P}}$ increases from 300 to 3,000 with increasing depth and low $Q_{\mathrm{P}}(\approx 200)$ in the lowermost $300 \mathrm{~km}$ of the mantle. The $\left(t_{\mathrm{m}}^{*}-t_{\mathrm{PcP}}^{*}\right)$ for both PREM and SL8 were calculated to be 0.25 for the epicentral distance ranges of $45-55^{\circ}$. Therefore, the depth variation of $Q_{\mathrm{P}}$ can be ignored for the following results.

For frequency-dependent $Q_{\mathrm{P}}$ in the lowermost mantle, Anderson and Given (1982) modeled that $Q_{\mathrm{P}}$ in the lowermost mantle is nearly flat $\left(Q_{\mathrm{P}} \approx 400\right)$ in the frequency range of $0.1-1 \mathrm{~Hz}$. Choy and Cormier (1986) suggested that little or no attenuation existed in the range of $0.01-5 \mathrm{~Hz}$ in the mantle below a depth of $2,000 \mathrm{~km}$. Here, we ignore the frequency dependence of $Q_{\mathrm{p}}$ in the lowermost mantle because of no evidence.

In practice, we estimated the spectral amplitude ratio using the Fast Fourier Transform. Since the data length was short, frequency ranges capable of being analyzed were narrow. To keep independency among the spectral ratios at different frequencies, and so as not to reduce the data number, we did not apply any smoothing operation to the spectra. A raw spectral ratio, $R_{i j}\left(f_{k}\right)$, was obtained for the $i$ th station, the $k$ th frequency and the $j$ th event. Here, we simply took the arithmetic averages of the spectral ratios, $\bar{R}_{j}^{\prime}\left(f_{k}\right)$, of $N_{j}$ stations for the $j$ th event after correcting a structural response and a focal mechanism defined as,

$$
\bar{R}_{j}^{\prime}\left(f_{k}\right)=\frac{1}{N_{j}} \sum_{i=1}^{N_{j}} R_{i j}^{\prime}\left(f_{k}\right),
$$

where, $R_{i j}^{\prime}\left(f_{k}\right)=1 / S_{j} \cdot R_{i j}\left(f_{k}\right) \cdot U_{\mathrm{PcP}}\left(f_{k}\right) / U_{\mathrm{P} 4 \mathrm{KP}}\left(f_{k}\right)$. The theory of spectrum shows that the standard deviation for each averaged spectrum is $\sqrt{\left(1 / N_{j}\right)}$ when the arithmetic average is considered. Since we wanted to see a real scatter of $R_{i j}^{\prime}(f)$ at each frequency, we adopted the standard deviation of

$$
\sigma_{j}\left(f_{k}\right)=\sqrt{\frac{1}{N_{j}-1} \sum_{i=1}^{N_{j}}\left(R_{i j}^{\prime}\left(f_{k}\right)-\bar{R}_{j}^{\prime}\left(f_{k}\right)\right)^{2}},
$$

and a standard error of $s e_{j}\left(f_{k}\right)=\sigma_{j}\left(f_{k}\right) / \sqrt{N_{j}}$. Then we substituted the average ratio of $R_{j}^{\prime}\left(f_{k}\right)$ and its error range $\left(R_{j}^{\prime}\left(f_{k}\right) \pm s e_{j}\left(f_{k}\right)\right)$ into Eq. (6) to obtain a value for $Q_{j}\left(f_{k}\right)$ and estimated the upper limit $Q_{j}\left(f_{k}\right)+E_{j}^{\mathrm{U}}\left(f_{k}\right)$ and the lower limit $Q_{j}\left(f_{k}\right)-E_{j}^{\mathrm{L}}\left(f_{k}\right)$ for the $j$ th event.

Next, we matched the individual measurement of $Q_{j}\left(f_{k}\right)$ to a frequency dependent $Q$ model with the relation of $Q_{\mathrm{P}}=a f^{b}$ using the least squares method. Taking the natural logarithm of the model form, we got $\ln Q_{\mathrm{P}}=\ln a+b \ln f$. The detailed equations we solved are given in the APPENDIX.

\section{Results}

We used seismographs which clearly recorded both PcP and P4KP (Fig. 5). The number of stations used in the analysis are 8,15 , and 8 for events 1,2 , and 3 , respectively. The PcP and P4KP phases were sampled in length of $6.4 \mathrm{~s}$ beginning $0.7 \mathrm{~s}$ prior to the observed travel times after passing a cosine-taper window at both ends. Background noise was sampled by the same length beginning at $7 \mathrm{~s}$ prior to the start of P4KP. Examples of PcP and P4KP amplitude spectra and the noise from stations KTJ, ATM, and SBT for Event 2 are shown in Fig. 10. The amplitude spectrum of the PcP phase was about 40 times larger than that of P4KP. The PcP spectrum had peak energy around the frequency of $1 \mathrm{~Hz}$, whereas that of P4KP was around the frequency
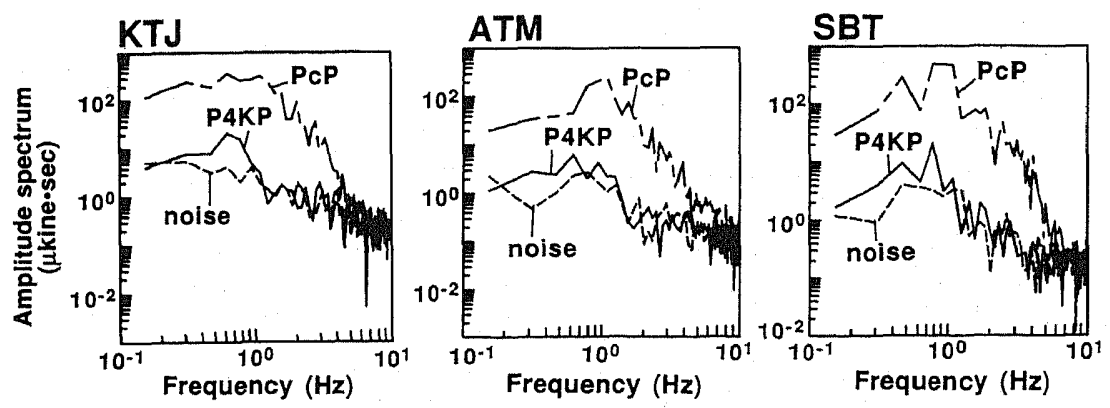

Fig. 10. Amplitude spectra of PcP, P4KP, and noise for Event 2 observed at the stations of KTJ (left), ATM (center), and SBT (right). 

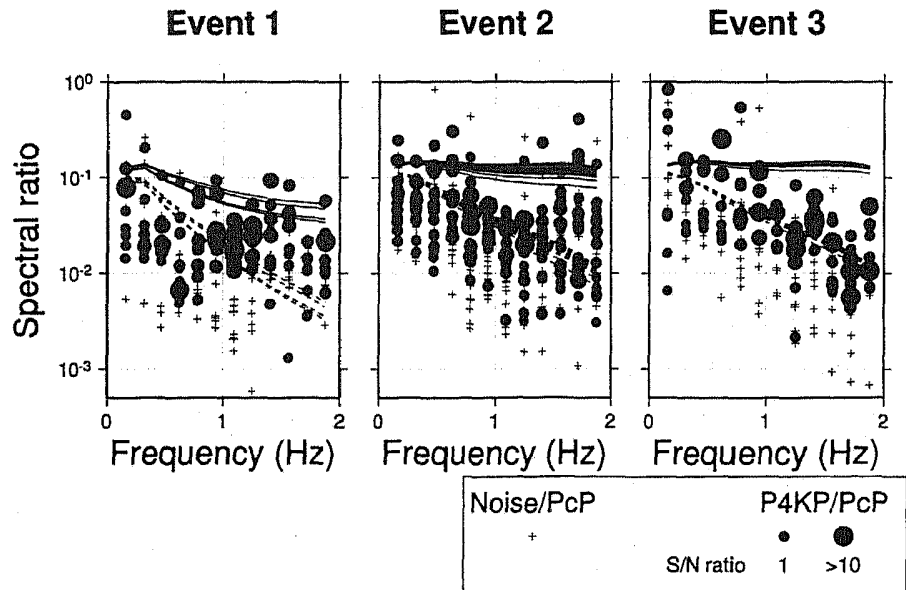

Fig. 11. Observed P4KP/PcP spectral amplitude ratios plotted by solid circles. Radii of the solid circles are proportional to signal-to-noise ratios of P4KP. Eight, fifteen, and eight stations are analyzed for events 1,2 , and 3 , respectively. Solid and dashed lines represent the predicted $\mathrm{P} 4 \mathrm{KP} / \mathrm{PcP}$ spectral ratios $\left(U_{\mathrm{P} 4 \mathrm{KP}}(f) / U_{\mathrm{PcP}}(f)\right) \cdot\left(A_{\mathrm{P} 4 \mathrm{KP}}(f) / A_{\mathrm{PcP}}(f)\right)$ as a function of frequency assuming that $Q_{\mathrm{P}}$ in the outer core is infinite and 5,000, respectively. We used the model SP6 for the velocity structure of the mantle and core, and PREM for $Q_{\mathrm{P}}$-structure of the mantle to obtain spectral ratios. Crosses are noise/PcP ratios.

of $0.6 \mathrm{~Hz}$. The spectra of $\mathrm{P} 4 \mathrm{KP}$ and the noise overlapped in frequencies greater than $2 \mathrm{~Hz}$. Therefore, we analyzed the spectral ratio of frequency ranges less than $2 \mathrm{~Hz}$.

Figure 11 shows the observed spectral ratios of $1 / S_{j} \cdot R_{i j}\left(f_{k}\right)$ as a function of frequency for events 1 , 2 , and 3 with the curves of theoretical amplitude ratios $\left(U_{\mathrm{P} 4 \mathrm{KP}}(f) / U_{\mathrm{PcP}}(f)\right) \cdot\left(A_{\mathrm{P} 4 \mathrm{KP}}(f) / A_{\mathrm{PcP}}(f)\right)$ assuming that the $Q_{\mathrm{P}}$ value of the outer core is infinite (solid lines) and 5,000 (dashed lines). The sizes of the solid circles are proportional to the signal-tonoise $(S / N)$ ratios of P4KP phases. The theoretical curves represent all the stations for each event. The spectral ratios of (the noise prior to $\mathrm{P} 4 \mathrm{KP}$ ) $/ \mathrm{PcP}$ are plotted by crosses for comparison. Almost all of the observed ratios $\left(R_{i j}\left(f_{k}\right)\right)$ were smaller than the theoretical curves for an infinite value of $Q_{\mathrm{P}}$, indicating that $Q_{\mathrm{P}}$ in the outer core is finite. The $R_{i j}\left(f_{k}\right)$ through the entire frequency range was approximately flat with respect to frequency. If $Q_{\mathrm{P}}$ is constant with respect to frequency, $R_{i j}\left(f_{k}\right)$ should monotonously decrease with increasing frequency, as shown by the theoretical curves with $Q_{\mathrm{P}}=5,000$. Therefore, the observed flat feature of $R_{i j}\left(f_{k}\right)$ suggests a frequency-dependent $Q_{\mathrm{P}}$.

Table 3 and Fig. 12 give $Q_{j}\left(f_{k}\right)$ values and their standard errors for each event obtained using Eqs. (6) and (7). When the values of $Q_{j}\left(f_{k}\right)$ or $Q_{j}\left(f_{k}\right)+$
$E_{j}^{\cup}\left(f_{k}\right)$ were infinite, such data were excluded. The $Q_{j}\left(f_{k}\right)$ values for Event 1 in the frequency range between 1 and $2 \mathrm{~Hz}$ were larger than those for events 2 and 3 . The values of error ranges $E_{j}^{\mathrm{U}}\left(f_{k}\right)$ and $E_{j}^{\mathrm{L}}\left(f_{k}\right)$ for Event 1 in the frequency range between 1 and $2 \mathrm{~Hz}$ were also larger than those for events 2 and 3. The data given in Table 3 were substituted in the equations given in the APPENDIX, giving us the solutions and standard deviations for $\ln a$ of $8.43 \pm 0.03$ and for $b$ of $0.55 \pm 0.07$. These results indicate that the $Q_{\mathrm{P}}$ value in the outer core increases with increasing frequency in the form of $Q_{\mathrm{P}}=$ $(4,600 \pm 100) f^{(0.55 \pm 0.07)}$.

Here, we estimate the errors of the calculated $Q_{\mathrm{P}}$ values based on the above model. The error propagation law is expressed by,

$$
\Sigma_{Q}=A \Sigma_{x} A^{t},
$$

where $\Sigma_{Q}$ is the error matrix of which the diagonal components are the variances of the calculated natural logarithm $Q_{\mathrm{P}}$ values at an arbitrary frequency, $A$ is the Jacobian matrix having the form of Eq. (A5) in the APPENDIX except that the frequency is arbitrarily selected and $\boldsymbol{\Sigma}_{\boldsymbol{x}}$ is the model-error covariance matrix for solutions of $\ln a$ and $b$. We obtained the upper and lower limits for $Q_{\mathrm{P}}$ values corresponding to twice the standard deviation from the best-fit model, as plotted by the thick lines in 
Table 3. Observed $Q_{j}\left(f_{k}\right), E_{j}^{\mathrm{U}}\left(f_{k}\right)$, and $E_{j}^{\mathrm{L}}\left(f_{k}\right)$ in the outer core determined from $\mathrm{P} 4 \mathrm{KP} / \mathrm{PcP}$ spectral ratios.

\begin{tabular}{|c|c|c|c|c|c|c|c|c|c|}
\hline \multirow{2}{*}{$\begin{array}{c}\text { Frequency } \\
f_{k}(\mathrm{~Hz})\end{array}$} & \multicolumn{3}{|c|}{ Event 1} & \multicolumn{3}{|c|}{ Event 2} & \multicolumn{3}{|c|}{ Event 3} \\
\hline & $Q_{1}\left(f_{k}\right)$ & $E_{1}^{\mathrm{U}}\left(f_{k}\right)$ & $E_{1}^{\mathrm{L}}\left(f_{k}\right)$ & $Q_{2}\left(f_{k}\right)$ & $E_{2}^{\mathrm{U}}\left(f_{k}\right)$ & $E_{2}^{\mathrm{L}}\left(f_{k}\right)$ & $Q_{3}\left(f_{k}\right)$ & $E_{3}^{\mathrm{U}}\left(f_{k}\right)$ & $E_{3}^{\mathrm{U}}\left(f_{k}\right)$ \\
\hline 0.15625 & & & & 1,600 & 700 & 400 & & & \\
\hline 0.31250 & 2,000 & 1,300 & 800 & 2,000 & 400 & 300 & 3,700 & 1,800 & 1,100 \\
\hline 0.46875 & 2,600 & 900 & 700 & & & & 3,300 & 1,200 & 800 \\
\hline 0.62500 & 3,200 & 1,300 & 1,000 & 7,400 & 4,200 & 2,300 & 5,600 & 4,800 & 2,300 \\
\hline 0.78125 & 5,200 & 2,200 & 1,500 & 4,800 & 1,200 & 900 & & & \\
\hline 0.93750 & 11,000 & 8,900 & 4,100 & 4,200 & 300 & 300 & & & \\
\hline 1.0938 & 6,800 & 1,400 & 1,200 & 4,100 & 400 & 300 & 5,400 & 600 & 500 \\
\hline 1.2500 & 13,000 & 5,800 & 3,600 & 5,600 & 1,900 & 1,600 & 4,500 & 900 & 900 \\
\hline 1.4063 & & & & 8,100 & 5,000 & 3,200 & 7,100 & 800 & 800 \\
\hline 1.5625 & 35,000 & $1,200,000$ & 20,000 & 7,200 & 1,100 & 1,000 & 4,900 & 500 & 500 \\
\hline 1.7188 & & & & 23,000 & 38,000 & 11,000 & 4,500 & 400 & 400 \\
\hline 1.8750 & 21,000 & 21,000 & 8,600 & 9,600 & 2,600 & 2,200 & 6,900 & 1,000 & 900 \\
\hline
\end{tabular}

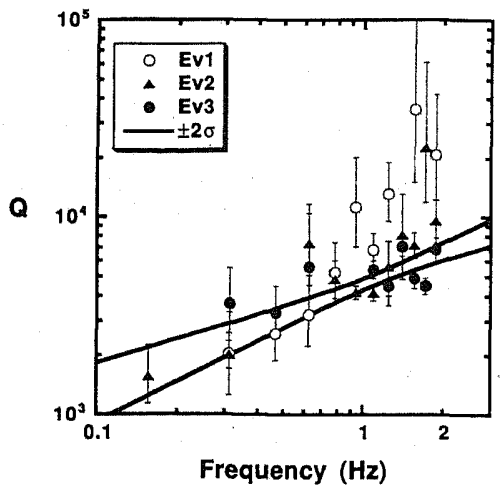

Fig. 12. $Q_{\mathrm{P}}$ values in the outer core as a function of frequency determined by $\mathrm{P} 4 \mathrm{KP} / \mathrm{PcP}$ spectral ratios. Open circles, solid triangles, and solid circles with their standard errors are $Q_{\mathrm{P}}$ values for events 1,2 , and 3 , respectively. Solid lines indicate upper and lower limits corresponding to twice the standard deviation ranges $( \pm 2 \sigma)$ from the best fit $Q_{\mathrm{P}}$ model of $Q_{\mathrm{P}}=(4,600 \pm$ 100) $f^{(0.55 \pm 0.07)}$.

Fig. 12. The limits indicate that the minimum error appears around the frequency of $1 \mathrm{~Hz}$. We obtained the model with $Q_{\mathrm{P}}$ values and their error ranges: about $2,500 \pm 500,4,600 \pm 300$, and $6,700 \pm 700$ at the frequencies of $0.3,1.0$, and $2.0 \mathrm{~Hz}$, respectively.

\section{Discussion}

5.1 Effect of scattering at the core-mantle boundary It is widely accepted that heterogeneity in the lowermost mantle $\left(\mathrm{D}^{\prime \prime}\right)$ and a $\mathrm{CMB}$ with rough topography yield scattered waves which are observed as precursors to PKIKP and PKKP (see the review by Bataille et al., 1990). Here, we discuss the influence of scattering near the $\mathrm{CMB}$ on the estimation of $Q_{\mathrm{P}}$ values in the outer core.

Since the path length in the $\mathrm{D}^{\prime \prime}$ for P4KP is longer than that for PcP (Fig. 1), we can infer that the influence of scattering in the $\mathrm{D}^{\prime \prime}$ for $\mathrm{P} 4 \mathrm{KP}$ is stronger than that for PcP. Scattered waves from the $D^{\prime \prime}$ is expected to be observed as a part of the P4KP coda because P4KP has the minimum travel time with respect to forward scattered waves in the $\mathrm{D}^{\prime \prime}$. The single-scattering theory predicts that the amplitude of scattered waves increases with the increasing square of frequency (Aki and Richards, 1980; Bataille et al., 1990). The amplitude of the primary wave decreases with increasing frequency, and $\mathrm{P} 4 \mathrm{KP}$ is possibly scattered by a CMB with rough topography when it is reflected inside the outer core. At this time, the scattered waves will be observed as precursors to $\mathrm{P} 4 \mathrm{KP}$, similar to those of PKKP (Chang and Cleary, 1978). The scattering theory also predicts that the amplitude of waves scattered by the $\mathrm{CMB}$ topography increases with increasing frequency (Bataille et al., 1990).

Since we did not find any precursors and coda which could possibly interpreted as scattered waves from near the $\mathrm{CMB}$, we could not assess quantitatively the influence of scattering near the $\mathrm{CMB}$ on the estimation of $Q_{\mathrm{P}}$ values in the outer core. 
If scattered waves arrive out of the time window analyzed in this study, the primary $\mathrm{P} 4 \mathrm{KP}$ waves would lose their high-frequency component and the $Q_{\mathrm{P}}$ values at high frequencies would possibly be underestimated. We found that $Q_{\mathrm{P}}$ values between $1 \mathrm{~Hz}$ and $2 \mathrm{~Hz}$ for Event 1 were higher than those for events 2 and 3 . This can be interpreted as follows. The epicentral distances in this study are $45-48^{\circ}$ for Event 1 , and $51-55^{\circ}$ for Events 2 and 3 (Fig. 5). Since the P4KP travel times in the $\mathrm{D}^{\prime \prime}$ for Event 1 are smaller than those for events 2 and 3 , the influence of scattering by the $\mathrm{D}^{\prime \prime}$ heterogeneity should be small. Alternatively, a regional variation in the properties of heterogeneous structures is suggested as discussed by van den Berg et al. (1978) for the interpretation of precursors to PKIKP. For example, the $\mathrm{D}^{\prime \prime}$ beneath the mid-point of the path Flores-Japan (Event 1) could be a relatively smooth region, and that of the path Hindu Kush (Afghanistan-USSR)-Japan (events 2 and 3) could be rough. We need further data and various epicentral distance samplings of many different regions to solve this issue.

\subsection{Geophysical implication for frequency-depen- dent $Q$ in the outer core}

Referring to the theory of absorption of sound in fluid caused by viscosity (Landau and Lifshitz, 1989), kinematic viscosity ( $v)$ is given by

$$
\nu=\alpha^{2} / 2 \pi f Q \text {. }
$$

When we put $\alpha=9 \mathrm{~km} / \mathrm{s}$ as the average P velocity in the outermost $1,000 \mathrm{~km}$ of the core, we obtain $v=1.7 \times 10^{8} \mathrm{~cm}^{2} / \mathrm{s}$ for $f=0.3 \mathrm{~Hz}$ with $Q=2,500$, $\nu=2.8 \times 10^{7} \mathrm{~cm}^{2} / \mathrm{s}$ for $f=1 \mathrm{~Hz}$ with $Q=4,600$, and $\nu=9.6 \times 10^{6} \mathrm{~cm}^{2} / \mathrm{s}$ for $f=2 \mathrm{~Hz}$ with $Q=6,700$. The viscosity apparently decreases with increasing frequency. The viscosity values estimated here are much larger than the theoretical estimation of $10^{-2} \mathrm{~cm}^{2} / \mathrm{s}$ for the molecular viscosity by Gans (1972), which is most frequently used in flowdynamics simulations for the outer core (see the review by Lumb and Aldridge, 1991). The estimation by Gans is based on the solid state of iron just as it starts melting. This means that his estimation of viscosity corresponds to that just above the inner core boundary (ICB). The molecular viscosity in the liquid outer core should be much lower than his estimation. Poirier (1988) showed that the viscosity of the outer core decreases from $6 \times 10^{-3} \mathrm{~cm}^{2} / \mathrm{s}$ at the ICB to $3 \times 10^{-3} \mathrm{~cm}^{2} / \mathrm{s}$ at the CMB assuming that the temperature of the core material varies adiabatically in the core, and that it is equal to the melting temperature at the ICB. The $Q$ values derived from the viscosities by both Gans and Poirier are $10^{13}-10^{14}$. Therefore, the small $Q_{\mathrm{P}}$ value of 4,600 at the frequency of $1 \mathrm{~Hz}$ in this study does not result from molecular viscosity but from some other mechanism such as relaxation (e.g., Stevenson, 1983). .

In some laboratory experiments for liquid metal, excess absorption that can be explained by neither viscosity nor thermal conductivity has been observed (e.g. Flinn et al., 1971). A viscoelastic theory of liquid metals with a single relaxation time gives the formulation of $Q$ as follows,

$$
Q^{-1}=\frac{k_{2}}{k_{1}} \frac{\omega \tau}{1+(\omega \tau)^{2}},
$$

where $\tau$ is the relaxation time and $k_{1}$ and $k_{2}$ are viscoelastic constants (see Kanamori and Anderson, 1977). The relaxation time of about $10^{-14} \mathrm{~s}$ (e.g., Nasch et al., 1994) yields $\omega \tau \ll 1$ under ultrasonic experiments at the frequency of several $\mathrm{MHz}$. Therefore, the theory based on these laboratory experiments predicts that the $Q$ value for liquid metal indicates a $1 / f$ dependence.

On the other hand, Anderson and Given (1982) proposed a model in which the $Q$ values in the outer core around $f=1 \mathrm{~Hz}$ are proportional to frequency, assuming that the relaxation time of the outer core material exists in the period range of $10-100 \mathrm{~s}$. Stevenson (1983) proposed that the resonance of an immiscible particle or blob in fluid yields anomalous absorption, supporting the frequency-dependent $Q$ model of Anderson and Given. In order to check how seismic observations can confirm frequencydependent $Q$ in the outer core, we compared the $Q$ values of this study and previous observational studies with several models. Figure 13 shows the observed and theoretical $Q$ values as a function of frequency $(f)$. The observed frequency-dependent $Q_{\mathrm{P}}$ obtained in this study grew more slowly with increasing frequency than the theoretical prediction of $Q \propto f$.

We recalculated $Q_{\mathrm{P}}$ from the data of Qamar and Eisenberg (1974), given in Table 1, since they obtained $Q_{P}$ values without any correction for the frequency dependence of PnKP reflection/transmission coefficients. Using their data with such a correction, Cormier and Richards (1976) obtained 


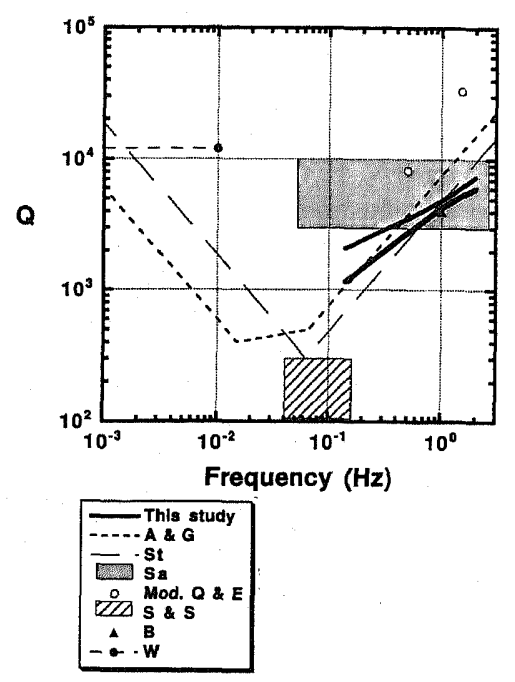

Fig. 13. $Q$ in the outer core as a function of frequency determined by this study and previous reports. Thick lines represent the upper and lower limits of $Q_{\mathrm{P}}$ values in the frequency range of $0.15-2 \mathrm{~Hz}$ obtained by this study. Bold (A and $\mathrm{G}$ ) and thin (St) dashed lines show the frequency-dependent $Q_{k}$ models of Anderson and Given (1982) and Stevenson (1983). Open circles (Mod. $Q$ and $E$ ) are recalculated $Q_{\mathrm{P}}$ values based on the data of Qamar and Eisenberg (1974), the solid triangle (B) corresponds to the results of Buchbinder (1972), and the dashed line with solid circles (W) represents the $Q_{k}$ model of Widmer et al. (1991). Hatched (Sa) and striped ( $S$ and $S$ ) regions indicate the $Q_{\mathrm{P}}$ values of Sacks (1971) and Suzuki and Sato (1970), respectively.

$Q_{\mathrm{P}}$ values of more than 10,000 , but they did not make a correction for the radiation pattern of the source. We replaced the ratios of geometrical spreading factor and reflection-transmission coefficient in Eq. (9) of Qamar and Eisenberg with frequency-dependent $U_{\mathrm{P} 7 \mathrm{KP}} / U_{\mathrm{P} 4 \mathrm{KP}}(f)$ calculated by the full-wave theory. Correction terms of $U_{\mathrm{P} 7 \mathrm{KP}} /$ $U_{\mathrm{P} 4 \mathrm{KP}}(f)$ are $0.1,0.19$, and 0.26 at $f=0.5,1.0$, and $1.5 \mathrm{~Hz}$, respectively. We used the data from the Sea of Okhotsk earthquake on August 30, 1970 recorded at stations JAS and ORV in the seismographic network of the University of California, Berkeley. We obtained averages for the observed amplitude ratios of $0.1,0.34$, and 0.31 at $f=0.5,1.0$, and $1.5 \mathrm{~Hz}$, respectively. Here, we used the same radiation pattern corrections as those used by Qamar and Eisenberg. The $Q$ value from Qamar and Eisenberg's data is less reliable than our result. The spectral ratio of $\mathrm{P} 7 \mathrm{KP} / \mathrm{P} 4 \mathrm{KP}$ cannot cancel out the heterogeneous structures near stations and sources because the take-off and incident azimuths of P7KP and P4KP are completely different. We obtained $Q_{\mathrm{P}}(f)$ of the outer core as $Q_{\mathrm{P}}(0.5 \mathrm{~Hz})=$ $8,000, Q_{\mathrm{P}}(1.0 \mathrm{~Hz})=\infty$ and $Q_{\mathrm{P}}(1.5 \mathrm{~Hz})=30,000$. These results do not deny that the $Q$ value at high frequency is larger than that at low frequency. The above $Q_{\mathrm{P}}$ values are generally higher than those obtained by $\mathrm{P} 4 \mathrm{KP} / \mathrm{PcP}$ ratios in this study.

Sacks (1971) analyzed the $P^{\prime} P^{\prime} / P$ spectral slope assuming a constant $Q$ value. He obtained that $Q_{\mathbf{P}}$ is $3,000-10,000$ in the frequency band $0.05<f<$ $2.7 \mathrm{~Hz}$, which is consistent with the $Q_{\mathrm{P}}$ values in other studies. However, the $Q_{\mathrm{p}}$ value in the frequency around $0.1 \mathrm{~Hz}$ obtained by Suzuki and Sato (1970) is 100-300, significantly different from the other estimates. Their frequency range around $0.1 \mathrm{~Hz}$ does not agree with the frequency range in this study, and the frequency dependence of $Q$ has not been confirmed yet in such a low frequency range.

Using free oscillation data, Widmer et al. (1991) obtained that bulk attenuation $Q_{k}$ is 12,000 in the frequency range of $0.3-10 \mathrm{mHz}$ with a frequencyindependent $Q$ model. However, the distribution of $Q_{k}$ in the Earth was still very poorly determined and more observations for $Q$ in radial modes is required.

$Q$ values, especially in the frequency range of $0.01-0.4 \mathrm{~Hz}$, have not been studied. In this study, we found that $Q_{\mathrm{P}}$ values in the outer core in the frequency range of $0.15-2 \mathrm{~Hz}$ increase more slowly with increasing frequency than $Q \propto f$ as predicted by the relaxation theory and absorption band model. If a simple extrapolation is allowed, the $Q_{\mathbf{P}}$ value at the frequency around $0.02 \mathrm{~Hz}$ is about 1,000 . This value of $Q_{\mathrm{P}}$ is 2-3 times larger than those predicted by the proposed models. Following the theory of Stevenson (1983), the minimum $Q_{\mathrm{P}}$ value and the frequency band for a flat $Q_{\mathrm{P}}$ value will provide important information in the discussion of the nature of outer core materials. We need new observations of various phases such as SnKP and SmKS and free oscillations by broadband instruments to reveal frequency-dependent $Q$ in frequency ranges less than $0.1 \mathrm{~Hz}$. 


\section{Conclusions}

The $\mathrm{P} 4 \mathrm{KP} / \mathrm{PcP}$ spectral amplitude ratio is investigated to reveal seismic attenuation and its frequency dependence in the outer core, using three intermediate-depth and deep earthquakes. We found that $Q_{\mathrm{P}}$ values in the outermost $1,000 \mathrm{~km}$ of the outer core are well explained by the frequencydependent $Q$ model taking the form of $Q_{\mathrm{P}}=(4,600 \pm$ 100) $f^{(0.55 \pm 0.07)}$. This indicates that the $Q_{\mathrm{P}}$ value in the outer core increases with increasing frequency. The observed frequency-dependent $Q_{\mathrm{P}}$ in the Earth's outer core increases more slowly with increasing frequency than $Q \propto f$ based on the relaxation mechanism of immiscible particles in the outer core (e.g., Anderson and Given, 1982; Stevenson, 1983).

We wish to express our thanks to all the staff at the seismic observatories attending the J-Array project for providing the seismograms. We also thank E. Garnero and two anonymous reviewers for critical reading, and $\mathrm{K}$. Yomogida for his kindly editorial efforts. The J-Array data acquisition has been supported by a Grant-in-Aid for Scientific Research (No. 03232101) from the Ministry of Education, Science, Sports and Culture of Japan. One of the authors (S.T.) was supported by Research Fellowships of the JSPS for Young Scientists. This study was partially supported by a Grant-in-Aid for Scientific Research from the Ministry of Education, Science, Sports and Culture, Japan (No. 0323).

\section{REFERENCES}

Adams, R. D., Multiple inner core reflections from a Novaya Zemlya explosion, Bull. Seismol. Soc. Am., 62, 1063-1071, 1972.

Aki, K. and P. G. Richards, Quantitative Seismology: Theory and Methods, Vols. I and II. W. H. Freeman, San Francisco, Cal., 932 pp., 1980.

Anderson, D. L., Bulk attenuation in the Earth and viscosity of the core, Nature, 285, 204-207, 1980.

Anderson, D. L. and J. F. Given, Absorption band $Q$ model for the Earth, J. Geophys. Res., 87, 3893-3904, 1982.

Anderson, D. L. and R. S. Hart, $Q$ of the Earth, J. Geophys. Res., 83, 5869-5882, 1978.

Bataille, K., R.-S. Wu, and S.M. Flatté, Inhomogeneities near the core-mantle boundary evidenced from scattered waves: A review, Pageoph, 132, 151-173, 1990.

Buchbinder, G. G. R., A velocity structure of the Earth's core, Bull. Seismol. Soc. Am., 61, 429-456, 1971.

Buchbinder, G. G. R., Travel times and velocities in the outer core from PmKP, Earth Planet. Sci. Lett., 14, 161-168, 1972.

Chang, A. C. and J. R. Cleary, Precursors to PKKP, Bull. Seismol. Soc. Am., 68, 1059-1079, 1978.

Choy, G. L. and V. F. Cormier, Direct measurement of the mantle attenuation operator from broadband $\mathrm{P}$ and S waveforms, J. Geophys. Res., 91, 7326-7342, 1986.

Cormier, V. F, and P. G. Richards, Comments on "The damping of core waves" by A. Qamar and A. Eisenberg, J. Geophys. Res., 81, 3066-3068, 1976.

Dziewonski, A.M. and D.L. Anderson, Preliminary reference Earth model, Phys. Earth Planet. Inter., 25, 297-356, 1981.

Dziewonski, A. M., A. L. Hales, and E. R. Lapwood, Papametrically simple Earth models consistent with geophysical data, Phys. Earth Planet. Inter., 10, 12-48, 1975.

Engdahl, E.R., Seismic waves within Earth's outer core: Multiple reflection, Science, 161, 263-264, 1968.

Flinn, J. M., J. Jarzynski, and T. A. Litovitz, Mechanism of volume viscosity in molten bismuth and lead, $J$. Chem. Phys., 54, 4331-4340, 1971.

Gans, R. F., Viscosity of the Earth's core, J. Geophys. Res., 77, 360-366, 1972.

Garnero, E. J., S. P. Grand, and D. V. Helmberger, Low P-wave velocity at the base of the mantle, Geophys. Res. Lett., 20, 1843-1846, 1993.

J-Array Group, The J-array program: System and present status, J. Geomag. Geoelectr., 45, 1265-1274, 1993.

Kanamori, H. and D. L. Anderson, Importance of physical dispersion in surface wave and free oscillation problems: Review, Rev. Geophys., 15, 105-112, 1977.

Kennett, B. L. N. and E. R. Engdahl, Traveltimes for global earthquake location and phase identification, Geophys. J. Int., 105, 429-465, 1991.

Landau, L. D. and E. M. Lifshitz, Fluid mechanics, 2nd ed., in Course of Theoretical Physics, Vol. 6, Pergamon Press, Oxford, 539 pp., 1989.

Lumb, L. I. and K. D. Aldridge, On viscosity estimations for the Earth's fluid outer core and core-mantle coupling, J. Geomag. Geoelectr., 43, 93-110, 1991.

Morelli, A. and A. M. Dziewonski, Body wave traveltimes and a spherically symmetric $\mathrm{P}$ - and S-wave velocity model, Geophys. J. Int., 112, 178-194, 1993.

Morita, Y., J-Array Seismograms, Disaster Prevention Research Institute, Kyoto University, Uji, 140 pp., 1994 (in Japanese).

Nasch, P. M., M. H. Manghani, and R. A. Secco, Sound velocity measurement in liquid iron by ultrasonic interferometry, J. Geophys. Res., 99, 4285-4291, 1994.

Poirier, J. P., Transport properties of liquid metals and viscosity of the Earth's core, Geophys. J., 92, 99-105, 1988. 
Qamar, A. and A. Eisenberg, The damping of core waves, J. Geophys. Res., 79, 758-765, 1974.

Richards, P. G., Calculation of body waves, for caustics and tunneling in core phases, Geophys. J. R. Astron. Soc., 35, 243-264, 1973.

Sacks, I. S., Anelasticity of the outer core. Annu. Rep. Dir. Dep. Terr. Mag., 1969-1970, 414-416, 1971.

Silver, P. G. and C. Bina, An anomaly in the amplitude ratio of SKKS/SKS in the range $100-108^{\circ}$ from the portable teleseismic data, Geophys. Res. Lett., 20 , 1135-1138, 1993.

Stevenson, D. J., Anomalous bulk viscosity of two-phase fluids and implications for planetary interiors, $J$. Geophys. Res., 88, 2445-2455, 1983.

Suzuki, Y. and R. Sato, Viscosity determination in the Earth's outer core from ScS and SKS phases, J. Phys. Earth, 18, 157-170, 1970.

van den Berg, A. P., S. A. P. L. Cloetingh, and D. J. Doornbos, A comparison of PKP precursor data from several seismic arrays, J. Geophys., 44, 499-510, 1978.

Widmer, R., G. Masters, and F. Gilbert, Spherically symmetric attenuation within the Earth from normal mode data, Geophys. J. Int., 104, 541-553, 1991.

Wright, C. Observations of multiple core reflections of the PnKP and SnKP type and regional variations at the base of the mantle, Earth Planet. Sci. Lett., 19, 453$460,1973$.

\section{APPENDIX}

In Sec. 3, we determined parameters $a$ and $b$ by the least squares method for a frequency-dependent $Q$ model in the form of $\ln Q=\ln a+b \ln f$. Its matrix representation is given by

$$
q^{\prime}=A^{\prime} x,
$$

where $q^{\prime}$ is the weighted data vector, $\boldsymbol{A}^{\prime}$ is the weighted Jacobian matrix, and $\boldsymbol{x}$ is the solution vector, which is expressed as

$$
\begin{gathered}
\boldsymbol{q}^{\prime}=\boldsymbol{W}^{1 / 2} \boldsymbol{q}, \\
\boldsymbol{A}^{\prime}=\boldsymbol{W}^{1 / 2} \boldsymbol{A}, \\
\boldsymbol{A}=\left(\begin{array}{cc}
\ln Q_{11}, \cdots, & \left.\ln Q_{j k}, \cdots, \ln Q_{J K}\right)^{t}, \\
\cdot & \ln f_{11} \\
1 & \ln f_{1 K} \\
1 & \ln f_{21} \\
\cdot & \cdot \\
1 & \ln f_{j k} \\
\cdot & \cdot \\
1 & \ln f_{J K}
\end{array}\right), \\
\boldsymbol{x}=(\ln a, b)^{\mathrm{t}} .
\end{gathered}
$$

Here the superscript " $t$ " means the transposed matrix, the subscript $j$ is for the $j$ th event and the subscript $k$ is for the $k$ th frequency: $J$ is the total number of events, $K$ is the total number of frequencies. The weight matrix is defined as,

$$
W=\left(\begin{array}{cccc}
w_{11} & & & \\
& \cdot & & \\
& & w_{j k} & \\
& & & \\
& & & w_{J K}
\end{array}\right),
$$

where

$$
\begin{gathered}
w_{j k}=1 / \sigma_{j k}^{2} \\
\sigma_{j k}=\frac{1}{2}\left[\left\{\ln \left(Q_{j k}+E_{j k}^{\mathrm{U}}\right)-\ln Q_{j k}\right\}\right. \\
\left.+\left\{\ln \left(Q_{j k}-E_{j k}^{\mathrm{L}}\right)-\ln Q_{j k}\right\}\right] .
\end{gathered}
$$

